\title{
FUNGSI MANTRA BELIAN PADA MASYARAKAT DAYAK MERATUS DI HULU SUNGAI TENGAH
}

\author{
Johan Arifin dan Fajarika Ramadania \\ STKIP PGRI Banjarmasin \\ Jalan Sultan Adam Komplek H. Iyus, No. 18 RT. 23 Banjarmasin, \\ Kalimantan Selatan, Kode pos 70121 \\ email: johankaltara@gamil.com dan baikhati27@gmail.com
}

\begin{abstract}
ABSTRAK
Dayak Meratus adalah istilah baru untuk menggantikan penyebutan Dayak Bukit bagi penduduk asli Kalimantan yang mendiami wilayah Pegunungan Meratus. Pegunungan ini membentang arah utara ke selatan, seolah membelah daratan Kalimantan Selatan menjadi dua sisi, barat dan timur. Suku Dayak tinggal di antara lembah-lembah pegunungan pada sisi barat dan timur. Pada sisi barat termasuk dalam wilayah Kabupaten Balangan, Hulu Sungai Selatan, Hulu Sungai Tengah, dan Kabupaten Banjar. Sisi timur meliputi wilayah Kabupaten Kotabaru dan Tanah Bumbu. Tulisan ini akan mengkaji tentang fungsi mantra upacara belian ditinjau dari antropologi sastra. Tujuan penelitian ini adalah mendeskripsikan fungsimantra belian pada masyarakat Dayak Meratus di Hulu Sungai Tengah. Jenis penelitian ini adalah penelitian kualitatif. Hasil penelitian ini adalah tentang Fungsimantra yang ditemukan dalam penelitian ini adalah Fungsi pengobatan/belian adalah untukmenyembuhkan, menghilangkan, atau mengobati rasa sakit yang diderita seseorang baik anakanak, orang dewasa, dan lanjut usia yang disebabkan oleh gangguan binatang, makhluk halus, orang gaib, bahkan ulah manusia itu sendiri.
\end{abstract}

Kata kunci: fungsi, matra belian, dayak meratus

\section{PENDAHULUAN}

Sastra lisan adalah karya sastra yang penyebarannya disampaikan dari mulut ke mulut secara turun temurun (Endraswara, 2013:151). Perkembangan sastra merupakan wadah yang melibatkan pihak manusia dan kehidupannya, karena sifatnya yang mudah diterima hal itulah yang membuatnya jadi lebih mudah untuk menyatu secara lisan dengan kehidupan manusia yang beragam. Keberagaman masyarakat yang hidup dimuka bumi ini memiliki suatu identitas dalam kelompoknya, satu diantaranya adalah sastra daerah. Ragam fungsi sastra lisan juga terdapat pada sastra daerah. Di Kalimantan Selatan khususnya di Desa Hantakan Kabupaten Hulu Sungai Tengah, masih mempertahankan sastra lisan tersebut yang berjenis "mantra". Mantra merupakan sastra lisan yang masih digunakan oleh masyarakat Dayak Meratus. Suku Dayak Meratus adalah suku masyarakat Desa Hantakan Kabupaten Hulu Sungai Tengah. 
Mantra merupakan seni kata yang khas. Kata-katanya dipilih cermat, dengan tujuan akan mengeluarkan irama-irama beraura magis ketika dibacakan secara berulang-ulang. Dalam penuturannya mantra diucapkan oleh seorang mamang atau orang yang paham akan hal yang akan dilakukan dalam proses pengobatannya. Mantra ini proses penyebarannya turun-temurun melalui tuturan yang disampaikan dari mulut ke mulut baik dari sanak keluarga atau orang lain yang merasa mampu ingin memiliki mantra tersebut dengan syarat memberikan mahar sebagai pengganti dalam pemberian mantra tersebut. Mantra bagi kehidupan masyarakat Dayak Meratus sangat bermanfaat serta mampu memberikan kesembuhan bagi masyarakat Dayak Meratus yang mengalami beberapa penyakit yang sering tidak terdiagnosa oleh medis dan bisa disembuhkan melalui ritual mantra-mantra tersebut.

Belian pada masyarakat dayak meratus di Kabupaten Hulu Sungai Tengah merupakan upacara yang dilakukan oleh masyarakat untuk mengobati orang sakit akibat bala atau penyakit kiriman orang lain. Masyarakat percaya bahwa Belian adalah penyembuhan yang paling manjur untuk mengobati orang sakit yang tidak sembuh dengan obat resep dokter, Belian dilakukan oleh mamang. Proses nya satu malam dengan menggunakan sesajen, ornamen-ornamen khas Belian, mantra, nyanyian dan taritarian. Belian sendiri menggunakan manta yang diucapkan oleh mamang agar penyakit tersebut pergi dari tubuh pasien yang sakit.

Sekarang ini sastra, khususnya penelitian sastra lisan berjenis mantra dan puisi lama yang keberadaannya hampir punah karena seiring majunya zaman dan ilmu teknologi. Sekarang sangat jarang ditemukan masyarakat yang masih mempercayai pengobatan tradisional seperti pengobatan yang menggunakan mantra. Sekarang ini anak-anak atau generasi muda jarang ditemukan yang percaya akan mantra atau kekuatan gaib yang sebenarnya sudah ada lama yang diwariskan secara turun-temurun oleh nenek moyang mereka. Khususnya masalah mantra dalam upacara Belian, orang zaman sekarang apabila sakit maka akan cepat-cepat dibawa ke dokter atau tenaga kesehatan lainnya karena majunya zaman, ilmu pengetahuan, dan teknologi. Maka pengobatan tradisonal seperti Belian tidak diminati bahkan tidak dipercaya lagi.

\section{METODE}

Penelitian yang berjudul Fungsi Mantra Belian pada Masyarakat Dayak Meratus di Kabupaten Hulu Sungai Tengahmenggunakan pendekatan antropologis. Metode yang digunakan adalah deskriptif analisis.

Fungsi Mantra Belian pada Masyarakat Dayak Meratus

di Hulu Sungai Tengah 
Jenis penelitian ini menggunakan jenis penelitian kualitatif yakni penelitian yang mengungkapkan gejala atau fenomena secara menyeluruh dan sesuai dengan konteks melalui pengumpulan data yang dilakukan peneliti sebagai instrument utama.

Subjek penelitian mantra dalam upacara belian, mantra ini dituturkan oleh mamang atau orang terdahulu yang mempunyai kemampuan untuk mengobati penyakit yang dialami baik itu anak-anak atau orang dewasa. Orang yang bisa disebut mamang adalah orang yang memiliki ilmu untuk mengobati orang sakit dan memiliki mantra belian, ilmu yang dimiliki oleh mamang diturunkan oleh orang tua terdahulu, karena untuk menjadi seseorang mamang harus belajar mendalam tentang tata cara, proses dan fungsi mantra belian.

Tempat penelitian yaitu di Desa Hantakan Kabupaten Hulu Sungai Tengah Kalimantan Selatan. Sumber data dari penelitian ini berupa sumber data primer dan sekunder. Sumber data primer adalah sumber data utama yang diperoleh langsung dari beberapa narasumber, sedangkan sumber data sekunder adalah sumber data yang diperoleh dari referensi berupa buku dan internet.

\section{HASIL DAN PEMBAHASAN}

Proses pengobatan dilakukan dirumah orang yang sakit karena biasanya upacara belian dilakukan oleh banyak orang seperti acara besar. Pemimpin acara adalah mamang yang akan mengobati pasien tersebut. Siang hari orang yang diundang akan membantu untuk persiapan upacara belian, seperti memasak, mempersiapkan alat dan bahan upacara belian. Pada malam hari uapacara belian dilaksanakan dari pukul 20.00-05.00 wita. Dalam prosesnya ada tiga yaitu, yang pertama baras paduduk, kedua tempurung jombu, dan yang ketiga puja. Proses yang pertama yaitu baras peduduk merupakan persiapan awal diiringi dengan tari-tarian dan musik khas dayak Meratus, tari-tarian dilakukan oleh mereka yang biasa menari mengelilingi ornamen yang dibuat dari reringgitan saat upacara belian. Proses yang kedua yaitu tempurung jombu merupakan menyusun sesajen dan alat yang digunakan untuk proses pengobatan. Proses yang ketiga adalah puja, puja adalah proses pengobatan atau belian yang merupakan pembacaan mantra oleh mamang. Biasanya pengucapan mantra berbedabeda antara penyakit tumpuan, pulukng, juata, ngolo utok, anak pea soyar, dan pekiek korik tetapi prosesnya sama saja yaitu dengan meghidupkan dupa dan kemenyan, kemudian pembacaan mantra oleh mamang. 
Proses pengobatan/panawar sengkonan adalah dengan upacara belian dengan menggunakan sesajen serta alat dan bahan seperti dupa, kemenyan dan air liur pasien. Mamang mengucapkan mantra secara berulang-ulang sambil membakar dupa, kemenyan dan mengoleskan air liur pasien secara berulang-ulang di tenggorokan yang sakit, setelah diolesi air liur duri atau tulang ikan yang tersangkut akan hancur dengan sendirinya. Sambil diiringi musik dan tari-tarian tradisional. Proses pengobatan dilaksanakan pada malam hari dari pukul 20.00-05.00 wita. Proses upacara belian dilakukan di rumah orang yang terkena penyakit tersebut. Sedangkan Proses panawar tawotn adalah dengan upacara belian dengan menggunakan sesajen serta alat dan bahan seperti dupa, kemenyan, beras, dan air putih. Mamang mengucapkan mantra berulang-ulang sambil membakar dupa, kemenyan dan mencampurkan beras dan air putih tersebut sambil membacakan mantra secara berulang-ulang. Sambil diiringi musik dan tari-tarian tradisional. Setelah dicampurkan lalu air itu diminum tiga kali dalam sehari.

Proses yang ketiga panawar manang kukut adalah dengan upacara belian dengan menggunakan sesajen serta alat dan bahan seperti dupa, kemenyan, kemiri, air putih, dan satu buah cabe rawit. Mamang mengucapkan mantra secara berulang-ulang sambil membakar dupa, kemenyan, kemiri dan menyemburkan air putih kewajah pasien setelah itu mengoleskan cabe rawit dipipi pasien pada bagian gigi yang sakit. Pasien tidak merasa kepedasan karena sudah dibacakan mantra. dan proses pengobatan yang keempat yaitu upal mendeh adalah dengan upacara belian dengan menggunakan sesajen serta alat dan bahan seperti dupa, kemenyan, air putih, dan minyak khusus yang dimiliki oleh mamang. Mamang mengucapkan mantra secara berulang-ulang sambil membakar dupa dan kemenyan, dan menyemburkan air putih kewajah pasien setelah itu mengoleskan minyak keperut pasien tiga kali putaran. Pasien akan merasa nyaman dan bisa buang air besar.

Dari hasil penelitian dengan beberapa narasumber dapat disimpulkan bahwa fungsi mantra pengobatan/belian adalah untuk menyembuhkan atau menghilangkan rasa sakit yang diderita seseorang baik anak-anak, orang dewasa, dan lanjut usia yang disebabkan oleh gangguan makhluk halus, orang gaib, binatang, bahkan ulah manusia itu sendiri, dan juga tak jarang penyakit tersebut dikatakan sebagian orang yaitu kapuhunan. Sedangkan makna mantra merupakan meminta kesembuhan kepada yang maha kuasa, karena atas izin-Nya penyakit tersebut diangkat dan disembuhkan

Sebuah mantra biasanya diawali dengan kalimat pembuka, kalimat pembuka yang umum diginakan dalam mantra ada dua jenis. Jenis pembuka panjang dan jenis pembuka pendek. Bagian pembuka pendek, misalnya Bismillah, Wah, Kur, Kur Semangat, dan lain-lain. Jenis pembuka yang 
panjang biasanya kelanjutan dari pembukaan yang pendek.Berikut adalah mantra atau bacaan yang digunakan oleh narasumber yang pertama yaitu Kursani (74 tahun). Berdomisili di Desa Hantakan Kabupaten Hulu Sungai Tengah Kalimantan Selatan.

\section{1) Fungsi Mantra untuk pengobatan/beliantumpuan}

Fungsi mantra tumpuan yaitu untuk menghilangkan bengkak pada anggota tubuh yang sakit akibat bengkak tersebut. Setelah sembuh anggota tubuh yang bengkak akan kembali seperti semula. Makna mantra tersebut adalah meminta kesembuhan kepada Tuhan Semesta Alam yang memiliki segalanya, memohon kesembuhan atas orang yang sedang sakit tersebut. Proses panawar tumpuan adalah dengan upacara belian dengan menggunakan sesajen serta alat dan bahan seperti dupa, kemenyan dan kemiri. Mamang mengucapkan mantra secara berulang-ulang sambil membakar dupa, kemenyan dan kemiri. Berhadapan dengan pasien sambil membacakan mantra dan kemiri yang dibakar tersebut baunya dihirup oleh pasien dan dioleskan kebagian tubuh yang sakit Sambil diiringi musik dan tari-tarian tradisional. Mereka yang menari mengelilingi ornamen yang dibuat dari reringgitan. Proses pengobatan dilaksanakan pada malam hari dari pukul 20.00-05.00 wita. Proses upacara belian dilakukan di rumah orang yang terkena penyakit tersebut.

\section{Mantra:}

Benuang tumbu ba jurang

Bengkala tumbu ba napu

Tumpuan naan ba ulutn

Sangga naan ba aku

Artinya :

Benuang tumbuh dijurang

Bengkala tumbuh dipantai

Tumpuan ada diorang

Penyembuhan ada diaku

\section{2) Fungsi Mantra untuk pengobatan/belianpulukng}

Fungsi panawar pulukng adalah untuk menghilangkan rasa sakit perut, sakit perut ini biasanya didalam perut rasanya seperti masuk angin. Makna mantra tersebut adalah meminta kesembuhan kepada Tuhan Semesta Alam yang memiliki segalanya, memohon kesembuhan atas orang yang sedang sakit tersebut. Proses panawar pulukng adalah dengan upacara belian dengan menggunakan sesajen serta alat dan bahan seperti dupa, kemenyan dan air untuk disembur dan diminum oleh orang yang 
sakit. Mamang mengucapkan mantra secara berulang-ulang sambil membakar dupa, kemenyan dan menyemburkan air tiga kali kewajah orang yang sakit, setelah disambur lalu air tersebut diminum. Sambil diiringi musik dan tari-tarian tradisional. Proses pengobatan dilaksanakan pada malam hari dari pukul 20.00-05.00 wita. Proses upacara belian dilakukan di rumah orang yang terkena penyakit tersebut.

\section{Mantara:}

Catik kapur

Kambang kapur

Anak tapah

Kapit katam

Penyakit pulukng

Awis hansur

Kono sumpah

Nabi adam

Artinya :

Ambil kapur

Kembang kapur

Anak tapah

Jepit katam

Penyakit sakit perut

Habis hancur

Terkena doa

Nabi adam

\section{3) Fungsi Mantra untuk pengobatan/belianjuata}

Fungsi panawar juata adalah untuk menghilangkan rasa sakit perut atau buang air besar yang terus menerus, sakit perut ini biasanya seperti diare dan disentri. Makna mantra tersebut adalah meminta kesembuhan kepada Tuhan Semesta Alam yang memiliki segalanya, memohon kesembuhan atas orang yang sedang sakit tersebut. Proses panawar juata adalah dengan upacara belian dengan menggunakan sesajen serta alat dan bahan seperti dupa, kemenyan dan air untuk disembur dan diminum oleh orang yang sakit. Mamang mengucapkan mantra secara berulang-ulang sambil membakar dupa, kemenyan dan menyambur air kewajah orang yang sakit, setelah disambur lalu air tersebut diminum. Sambil diiringi musik dan tari-tarian tradisional. Proses pengobatan/panawar juata mirip dengan proses panawar pulukng tetapi mantra yang diucapkan berbeda. Proses pengobatan 
dilaksanakan pada malam hari dari pukul 20.00-05.00 wita. Proses upacara belian dilakukan di rumah orang yang terkena penyakit tersebut.

\section{Mantra:}

Danggi dangga

Imbat ruoy

Pating tali mati

Iko anak naga

Kono jampi ku situ

Artinya :

Atas bawah

Pergilah kamu sakit

Potong tali mati

Kamu anak naga

Terkena doa ku ini

\section{4) Fungsi Mantra untuk pengobatan/belianngolo utok}

Fungsi panawar ngolo utok adalah untuk menghilangkan rasa sakit kepala yang berlebihan atau sakit kepala yang terus menerus sampai orang tidak bisa berdiri. Makna mantra tersebut adalah meminta kesembuhan kepada Tuhan Semesta Alam yang memiliki segalanya, memohon kesembuhan atas orang yang sedang sakit tersebut. Proses panawar ngolo utok adalah dengan upacara belian dengan menggunakan sesajen serta alat dan bahan seperti dupa, kemenyan, daun derangau, dan air untuk disambur dan diminum oleh orang yang sakit. Mamang mengucapkan mantra secara berulang-ulang sambil membakar dupa, kemenyan, dan daun derangau sambil menyambur air kewajah orang yang sakit. Sambil diiringi musik dan tari-tarian tradisional. Proses pengobatan dilaksanakan pada malam hari dari pukul 20.00-05.00 wita. Proses upacara belian dilakukan di rumah orang yang terkena penyakit tersebut.

\section{Mantra}

Besesia besesintang

Serasak serusuk

Waringin hujung panggung

Artinya :

Dibakar dihilangkan

Disembuhkan semuanya 
Diiring ujung panggung

\section{5) Fungsi Mantra untuk pengobatan/beliananak pea soyar}

Fungsi panawar anak pea soyar adalah untuk membuat anak yang menangis tanpa sebab menjadi berhenti. Makna mantra tersebut adalah meminta kesembuhan kepada Tuhan Semesta Alam yang memiliki segalanya, memohon kesembuhan atas orang yang sedang sakit tersebut. Proses panawar anak pea soyar adalah dengan upacara belian dengan menggunakan sesajen serta alat dan bahan seperti dupa, kemenyan, daun itak pori, dan air untuk disemburkan tiga kali kepada anak yang sakit. Mamang mengucapkan mantra secara berulang-ulang sambil membakar dupa, kemenyan, dan daun itak pori sambil menyembur air kewajah anak yang sakit. Sambil diiringi musik dan tari-tarian tradisional. Proses pengobatan dilaksanakan pada malam hari dari pukul 20.00-05.00 wita. Proses upacara belian dilakukan di rumah orang yang terkena penyakit tersebut.

\section{Mantra:}

Uwe pate keraput lawut putatn

Jampi itak pori mate

Itak pori jauh juhatn

Artinya :

Rotan mati terjerat pohon besar

Doa nenek Pori meninggal

Nenek pori jauh disana

\section{6) Fungsi Mantra untuk pengobatan/belianpekiek korik}

Fungsi panawar pekiek korik adalah untuk membuat anak yang menangis tanpa air mata akibat gangguan jin menjadi berhenti dan bisa tidur. Makna mantra tersebut adalah meminta kesembuhan kepada Tuhan Semesta Alam yang memiliki segalanya, memohon kesembuhan atas orang yang sedang sakit tersebut. Proses panawar pekiek korik adalah dengan upacara belian dengan menggunakan sesajen serta alat dan bahan seperti dupa, kemenyan, daun itak pori, dan abu arang untuk dihamburkan didepan pintu. Mamang mengucapkan mantra secara berulang-ulang sambil membakar dupa, kemenyan, dan daun itak pori sambil menghamburkan abu tiga kali didepan pintu rumah anak yang sakit pekiek korik. Sambil diiringi musik dan tari-tarian tradisional. Proses pengobatan dilaksanakan pada malam hari dari pukul 20.00-05.00 wita. Proses upacara belian dilakukan di rumah orang yang terkena penyakit tersebut. 


\section{Mantra:}

Bembare rere

Belimbingan suakng lunjek

Mato ontu gawis pare

Sirom dondom

Mato uok ontu

Artinya :

Terpejam semuanya

Yang berada dirawa-rawa

Mata hantu habis terpejam

Gelap gulita

Mata semua hantu

\section{7) Fungsi Mantra untuk pengobatan/belianporoh}

Fungsi pengobatan poroh adalah membuat luka darah yang tidak bisa kering menjadi kering dan kulit yang terluka menjadi sembuh seperti semula. Makna mantra tersebut adalah meminta kesembuhan kepada yang maha kuasa, karena atas izinNya penyakit tersebut diangkat dan disembuhkan. Proses panawar poroh adalah dengan upacara belian dengan menggunakan sesajen serta alat dan bahan seperti dupa, kemenyan dan minyak khusus yang dimiliki oleh mamang. Mamang mengucapkan mantra secara berulang-ulang sambil membakar dupa, kemenyan dan mengoleskan minyak pada luka tersebut, setelah diolesi minyak tersebut darah akan kering dan luka akan cepat sembuh. Sambil diiringi musik dan taritarian tradisional. Proses pengobatan dilaksanakan pada malam hari dari pukul 20.00-05.00 wita. Proses upacara belian dilakukan di rumah orang yang terkena penyakit tersebut

Kur semangat...Kur semangat...

Meang awis meang

Raya ba upak ne

Radu at mulek

pe sara hadi

Jari meang

Radu manang

Artinya :

Kering jadi habis kering

Darah di kulit nya

Berhentilah kembali

Ke asal seperti semula

Jadi kering

Berhenti sakit. 


\section{8) Fungsi Mantra untuk pengobatan/belianmanang wuntung}

Fungsi pengobatan manang wuntung adalah meredakan sakit di dalam perut agar perut pasien menjadi lega. Makna mantra tersebut adalah meminta kesembuhan kepada yang maha kuasa, karena atas izinNya penyakit tersebut diangkat dan disembuhkan. Proses panawar manang wuntung pada anak-anak adalah dengan meminum air yaitu tiga kali sehari yang sudah dibacakan mantra oleh mamang. Sedangkan pada orang dewasa adalah dengan upacara belian dengan menggunakan sesajen serta alat dan bahan seperti dupa, kemenyan dan air putih. Mamang mengucapkan mantra secara berulang-ulang sambil membakar dupa, kemenyan dan menyemburkan air kewajah orang yang sakit, setelah itu air diminum dan perut yang sakit akan cepat sembuh. Sambil diiringi musik dan tari-tarian tradisional. Proses pengobatan dilaksanakan pada malam hari dari pukul 20.00-05.00 wita. Proses upacara belian dilakukan di rumah orang yang terkena penyakit tersebut.

\section{Mantra}

Kur semangat.. kur semangat..

Kual kual

Radu at radu

Udak manang wuntung

Kual kual at

Se mulah manang sio

Jari radu jari waras ise

Artinya :

Keluarlah keluarlah

Sembuhlah sembuhlah

Yang menyebabkan sakit perut

Keluarlah keluarlah

Yang membuat sakit itu

Menjadi sembuh menjadi sehat

\section{9) Fungsi Mantra untuk pengobatan/beliankelato}

Fungsi pengobatan kelato adalah membuat kulit yang gatal-gatal menjadi tidak gatal lagi dan menjadi sembuh seperti semula. Makna mantra tersebut adalah meminta kesembuhan kepada yang maha kuasa, karena atas izin-Nya penyakit tersebut diangkat dan disembuhkan. Proses panawar pada anak-anak dan orang dewasa sama saja yaitu dengan mengoleskan minyak khusus yang diberikan oleh mamang yang sudah dibacakan mantra secara berulang-ulang oleh mamang tersebut dengan upacara belian, dengan menggunakan sesajen serta alat dan bahan seperti dupa dan kemenyan. Sambil diiringi 
musik dan tari-tarian tradisional. Proses pengobatan dilaksanakan pada malam hari dari pukul 20.0005.00 wita. Proses upacara belian dilakukan di rumah orang yang terkena penyakit tersebut.

\section{Mantra}

Kakap kakap ai wa kakap

Kelato sio maeh radu

Ku sumpah kelato radu

Maeh iko waras gane

Artinya :

Gatal gatal jangan gatal

Gatal itu supaya sembuh

Ku doakan penyakit itu sembuh

Supaya kamu menjadi sehat

\section{0) Fungsi Mantra untuk pengobatan/beliansengkonan}

Fungsi pengobatan sengkonan adalah duri atau tulang ikan yang tersangkut akan hancur dengan sendirinya dan pasien tidak merasa sakit lagi. Makna mantra tersebut adalah meminta kesembuhan kepada yang maha kuasa, karena atas izinNya penyakit tersebut diangkat dan disembuhkan. Proses panawar sengkonan adalah dengan upacara belian dengan menggunakan sesajen serta alat dan bahan seperti dupa, kemenyan dan air liur pasien. Mamang mengucapkan mantra secara berulang-ulang sambil membakar dupa, kemenyan dan mengoleskan air liur pasien secara berulang-ulang di tenggorokan yang sakit, setelah diolesi air liur duri atau tulang ikan yang tersangkut akan hancur dengan sendirinya. Sambil diiringi musik dan tari-tarian tradisional. Proses pengobatan dilaksanakan pada malam hari dari pukul 20.00-05.00 wita. Proses upacara belian dilakukan di rumah orang yang terkena penyakit tersebut.

\section{Mantra}

Tulang hansur

Tulang hansur

Radu sengkonan iko

Radu sengkonan iko

Lonuh lonuh lalatn ne

Sara sunge jak rayo pe awa

Artinya :

Duri/tulang ikan hancur

Duri/tulang ikan hancur

Sembuhlah sembuhlah kamu

Sembuhlah sembuhlah kamu 
Lancarlah lancarlah jalannya

Seperti sungai yang mengalir

\section{1) Fungsi Mantra untuk pengobatan/beliantawotn}

Fungsi pengobatan tawotn adalah menyembuhkan orang yang keracunan, baik itu keracunan bau-bau yang busuk atau keracunan makanan, bisa dialami oleh orang dewasa dan anak-anak. Makna mantra tersebut adalah meminta kesembuhan kepada yang maha kuasa, karena atas izinNya penyakit tersebut diangkat dan disembuhkan. Proses panawar tawotn adalah dengan upacara belian dengan menggunakan sesajen serta alat dan bahan seperti dupa, kemenyan, beras, dan air putih. Mamang mengucapkan mantra berulang-ulang sambil membakar dupa, kemenyan dan mencampurkan beras dan air putih tersebut sambil membacakan mantra secara berulang-ulang. Sambil diiringi musik dan taritarian tradisional. Setelah dicampurkan lalu air itu diminum tiga kali dalam sehari. Proses pengobatan dilaksanakan pada malam hari dari pukul 20.00-05.00 wita. Proses upacara belian dilakukan di rumah orang yang terkena penyakit tersebut.

\section{Mantra}

Umpi umpi

Umpi umpi

Tulak iko se jari tawotn

Mulah ulun situ doho waras

Aku be mohon ulun situ waras

Te umpi awis se jari tawotn

Artinya :

Buang buanglah

Buang buanglah

Pergi kamu yang menjadi racun

Membuat saudara ku menjadi sakit

Aku memohon penyembuhan untuk saudara ku ini

Terbuang habis yang menjadi racun

\section{2) Mantra untuk pengobatan/belianmanang kukut}

Fungsi pengobatan manang kukut adalah untuk menghilangkan sakit pada gigi. Makna mantra tersebut adalah meminta kesembuhan kepada yang maha kuasa, karena atas izinNya penyakit tersebut diangkat dan disembuhkan. Proses panawar manang kukut adalah dengan upacara belian dengan menggunakan sesajen serta alat dan bahan seperti dupa, kemenyan, kemiri, air putih, dan satu buah cabe rawit. Mamang mengucapkan mantra secara berulang-ulang sambil membakar dupa, kemenyan, 
kemiri dan menyemburkan air putih kewajah pasien setelah itu mengoleskan cabe rawit dipipi pasien pada bagian gigi yang sakit. Pasien tidak merasa kepedasan karena sudah dibacakan mantra. Sambil diiringi musik dan tari-tarian tradisional. Proses pengobatan dilaksanakan pada malam hari dari pukul 20.00-05.00 wita. Proses upacara belian dilakukan di rumah orang yang terkena penyakit tersebut.

\section{Mantra}

Kukut ko, kukut ko

Katur katur katur nanam ne

Radu ngingol radu rinyut

Tawas ku maeh waras

Kate kuman kate sundro

Artinya :

Gigi mu, gigi mu

Kesemutan kesemutan kesemutan lah rasanya

Berhenti sakit berhenti nyeri

Obat ku menjadi sembuh

Bisa bicara bisa makan seperti semula

\section{3) Fungsi Mantra untuk pengobatan/belian upal mendeh}

Fungsi pengobatan upal mendeh adalah agar pasien bisa buang air besar. Makna mantra tersebut adalah meminta kesembuhan kepada yang maha kuasa, karena atas izin-Nya penyakit tersebut diangkat dan disembuhkan. Proses panawar upal mendeh adalah dengan upacara belian dengan menggunakan sesajen serta alat dan bahan seperti dupa, kemenyan, air putih, dan minyak khusus yang dimiliki oleh mamang. Mamang mengucapkan mantra secara berulang-ulang sambil membakar dupa dan kemenyan, dan menyemburkan air putih kewajah pasien setelah itu mengoleskan minyak keperut pasien tiga kali putaran. Pasien akan merasa nyaman dan bisa buang air besar. Sambil diiringi musik dan tari-tarian tradisional. Proses pengobatan dilaksanakan pada malam hari dari pukul 20.00-05.00 wita. Proses upacara belian dilakukan di rumah orang yang terkena penyakit tersebut.

\section{Mantra}

Repuput repuput nain ne

Repuput repuput nain ne

Se upal mendeh so kate nengkual

Sio kakatn ku ampe se kuasa

Artinya : 
Repuput repuput bunyi nya

Repuput repuput bunyi nya

Yang tidak bisa buang air besar bisa mengeluarkannya

Itulah permintaan ku kepada yang kuasa

\section{SIMPULAN}

Berdasarkan hasil penelitian dan pembahasan tentang Fuingsi mantra Belian Pada Masyarakat Dayak Meratus di Kabupaten Hulu Sungai Tengah, maka hasil penelitian ini dapat disimpulkan. Fungsi mantra pengobatan/belian adalah untuk menyembuhkan, menghilangkan, atau mengobati rasa sakit yang diderita seseorang baik anak-anak, orang dewasa, dan lanjut usia yang disebabkan oleh gangguan binatang, makhluk halus, orang gaib, bahkan ulah manusia itu sendiri.

\section{SARAN}

1. Bagi peneliti, bermanfaat sebagai sumbangan bagi pengembangan khazanah keilmuan dalam bidang sastra khususnya mantra dalam pengobatan, dan mampu menumbuhkan minat kalangan akademis untuk melakukan penelitian lebih lanjut tentang mantra pengobatan yang ada pada masyarakat Dayak Meratus di Kabupaten Hulu Sungai Tengah.

2. Bagi pembaca, memberikan wawasan dan pemahaman kepada masyarakat khususnya para generasi muda tentang fungsi mantra belian dalam pengobatan pada masyarakat Dayah Meratus di Kabupaten Hulu Sungai Tengah.

\section{DAFTAR RUJUKAN}

Endraswara, S. 2013. Metodologi Penelitian Sastra.Yogyakarta: CAPS (Center For Academic Publishing Service).

Inayati, S. 2017. Fungsi, Makna, dan Proses Mantra Bahakong/ Panawar Kapidaraan di Kecamatan Kelua Kabupaten Tabalong. Skripsi tidak diterbitkan. Banjarmasin: STKIP PGRI Banjarmasin.

Jumiati. 2017. Transformasi Upacara Belian ke dalam Tari Gitang Paser. Jurnal Skripsi,(Online),(http://ejounals.unmul.ac.id/index.php/JBSSB/article/view/898). Diakses pada 01 mei 2019.

Koentjaraningrat. 2009. Pengantar Ilmu Antropologi. Jakarta: Rineka Cipta.

Laelasari, N. 2008. Kamus Istilah Sastra. Bandung: Penerbit Nuansa Aulia

Ratna, N. K.. 2013. Stilistika Kajian Puitika Bahasa, Sastra, dan Budaya. Yogyakarta: Pustaka Pelajar. 
Sugiarto, E. 2015. Mengenal Sastra Lama Jenis, Defisi, Ciri, Sejarah Dan Contoh.Yogyakarta: Andi.

Sulistyowati, E. dan Ganie, T. N. 2015. Sastra Banjar Genre Lama Bercorak Puisi. Banjarmasin: Tuas Media.

dan Tarman Effendi Tarsyad. 2015. Kajian PuisiStruktural, Semiotik, Stilistika, Sosiologi, Antropologi, dan Bandingan. Banjarbaru : Scripta Cendekia. . 2018. Kajian ProsaFiksi. Banjarbaru : Scripta Cendekia.

Syahril. 2018. Mantra dalam Pengobatan Masyarakat Di Desa Setarap Kecamatan Satui Kabupaten Tanah Bumbu. Skripsi Tidak Diterbitkan. Banjarmasin: STKIP PGRI Banjarmasin.

Tim Penyusun.2016. Pedoman Penulisan Skripsi. Banjarmasin: Sekolah Tinggi Keguruan Dan Ilmu Pendidikan Persatuan Guru Republik Indonesia (STKIP PGRI) Banjarmasin.

Zaidan, A. R., dkk.2007. Kamus Istilah Sastra. Jakarta: Balai Pustaka. 